\title{
Planning and implementing a cross-training program
}

\author{
By Peggy Johnson
}

\section{Multiskilled employees can make services more effective}

ross-training is a win-win proposition for libraries because:

- staff members enhance their job skills;

- barriers between units become less rigid;

- empathy with and support for coworkers increase;

- communication across departmental lines improves;

- services and operations improve through increased insight into the "big picture"; and

- libraries can respond more quickly to challenges when they have staff members who are able to perform several jobs.

Cross-training is the process of teaching an individual new job skills in a position other than his or her usual one. Staff must be able to acquire the necessary job skills through handson training. Cross-training offers one approach to breaking down barriers between geographic and functional units. It can be considered one alternative to matrix management or formally restructuring into teams. The benefits are similar, but without the stress of fundamentally redesigning the organization.

While benefits can be impressive, a library should evaluate cross-training to confirm that it is appropriate in the local context. If the decision is to go forward, careful planning is essential. This article identifies factors to consider when planning a cross-training program and presents a project in the University of Minnesota St. Paul Campus Libraries as one model for planning and implementing an effective program.

\section{Why cross-training?}

All projects should begin with a clear understanding of what will be accomplished. Why is cross-training needed? What are the goals? What are the benefits? To whom do these benefits accrue? Most libraries using cross-training discover that both the staff and the library see gains. For cross-training to succeed, all parties must recognize what they have to gain.

Cross-training benefits from the staff perspective are numerous. Staff members can acquire new job skills. Staff members with a broader skill base and wider experience are better prepared for career advancement. They can move more easily to positions in the library outside their "home" unit when they have a repertoire of job skills. Variety and challenge in work increase job satisfaction. People like knowing more about how colleagues do their jobs. The risks of repetitive motion syndrome are reduced when staff members have more variety and an option of moving to different types of work for a time. The trainer has the satisfaction of passing on his or her expertise and sharing competence with others. During cross-training, the trainee functions as an apprentice who is learning the tricks of the trade from skillful job performers.

Libraries also gain in many ways. They develop a larger pool of employees who can step in when a unit is short-staffed. This means an increased ability to respond to crises by providing trained and willing staff members to meet deadlines, fill in for a sick colleague, or handle unusually heavy service loads. Staff members who understand several aspects of library operations and services are more effective. They have increased empathy and can better understand each other's perspectives, concerns, and 
problems. Individuals comprehend the flow of work through the library and how work done in one area affects work clone in another. Technical services staff gain insight into how the records they create are used and learn the satisfaction (and frustration) of dealing with patrons. Public services staff gain an understanding of the complexities of working within local and national standards and the volume of materials that move through the units. The library benefits through having staff members who are well informed and well rounded in their ability to perform related job functions. Libraries can experience improved operations, services, and communication.

\section{One approach}

In the spring of 1994 the St. Paul Campus Li braries (SPCL) initiated a program of cross-train ing for staff members. Initial goals were to 1) increase the number of staff members able to perform key job functions in other units and fill in when needed, and 2) increase understanding across units and jobs. At the time this project was initiated, SPCL consisted of a large central library, five on-campus branch libraries, and one remote branch library 20 miles away. The central library, in addition to housing central reference and circulation services, included support units that served all St. Paul service points. These were interlibrary loan, book acquisitions, serials management, bindery preparation and marking, cataloging, shipping and receiving, and an administrative office. SPCL had 32 fulltime staff members, about one-third of whom were professional librarians, and several hours a week of student assistants.

The organizational structure had been a traditional mix of functional unis (serials management, interlibrary loan service, etc.) and client-based units (forestry, plant pathology, and other subjectspecific branch libraries) with limited opportunities for staff members to move to new positions. A technical services staff member tended to remain in technical services and a public services staff person was likely to remain in public services. Many staff members had not spent time in or even visited other units (especially the branch libraries) in SPCL. Planners quickly realized that an orientation to units and their services had to be an early part of a crosstraining project.
The project was proposed initially as a solution to problems providing coverage in the smaller branches cluring staff absences. The idea of cross-training was discussed in two meetings - one of professional librarians and unit heads and another for all staff. Attendees suggested potential benefits of cross-training, both personally and for SPCL, and they identified possible problems. People agreed not all positions had components suitable for cross-training, but everyone was interested in learning more about their colleagues' responsibilities and getting an in-depth orientation to work in each unit. Unit heads were willing to support staff participation. This widespread willingness to give cross-training a try was critical. Without interest and support, cross-training participants will not sustain the motivation to learn and apply new job skills.

Four volunteers stepped forward to plan and guide the project, which was sponsored by the SPCL assistant director. The planning group developed learning objectives and activities for the program. They designed a generic syllabus or outline of information to be covered in each unit and prepared a checklist of handouts that the trainees would receive. Because some units were less suited to cross-training, the emphasis in these areas was on an overview of the unit and its work. Other units, those with certain tasks that could be learned in a short period
The widespread willingness to give cross-training a try was critical. Without interest and support, participants will not sustain the motivation to learn and apply new job skills.

and that could be regained with an "aid," prepared packets that would serve as simple "howto-do-it" reminders. These packets included floor plans, procedures for opening and closing the unit, and information about keys, operating equipment (fax machines, phones, photocopiers, etc.), special services and collections, and procedures for basic services.

All SPCL staff members were encouraged to participate in site visits and cross-training, though no one was required to do so. The planning group coordinated and scheduled the ses- 
sions, which lasted between 45 minutes and an hour and half and were offered to groups of five or less. Each unit, except the remote branch library, scheduled several sessions. Site visits, which provided an overview of work flow and responsibilities and did not include hands-on training, were as well attended as those that included cross-training. The training portions of the project concentrated on entry-level public service work-opening units, answering phones, circulating materials, answering directional questions, orienting users to services and facilities, etc. Each session's goal was to convey an understanding of what staff in that unit did and the competencies needed to open and close the unit and provide basic services.

\section{Evaluating the program}

The planning group followed up on the four weeks of site visits and cross-training (in which nearly all staff members participated) with an evaluation. They wanted to know what went well, what could be improved, and how staff members felt about the project. The brief evaluation survey also asked people to indicate units in which they would like to work on an "oncall/as needed" basis, on special projects, and (perhaps) through regular part-time assignments. Survey responses confirmed informal comments made during the project. SPCL staff members were delighted! They liked learning what their colleagues did and liked explaining their own jobs. They appreciated the opportunity to try other types of library work and were eager to help out when they could.

\section{Feature your collection on the cover of C\&RL News}

CGRL News wants to feature aesthetically pleasing photos of items from library collections on its covers. If you have material in your library's collections that you think would make an attractive CERL News cover, please send us a photograph or a color photocopy and a brief description of the item and the collection. Photos may be either color or black-and-white and should be $5^{\prime \prime} \times 7^{\prime \prime}$ or $8^{\prime \prime} \times 10^{\prime \prime}$. Illustrations with a vertical orientation work best. Send to: CERL News Covers, 50 E. Huron St., Chicago, IL 60611.
The main problem or concern raised was the impact on a "home" unit of staff working in another unit. Supervisors wanted to know if their units would get paid back for time given to another unit. Individuals worried about performance evaluation if they fell behind in their primary responsibilities because of work in another unit. There are no formula-based answers to these questions. Some types of work are easier to handle in a short-term, superficial way. Other units will see no direct benefits from cross-training. Supervisors and staff members agreed to concentrate on the "greater good" and to focus on SPCL as a system in which assisting in any area benefits the whole. A few simple ground rules were affirmed.

- When a unit will be short-staffed or has a special need, a call for help is made on the SPCL staff listserv.

- Units weigh advantages of requesting help from permanent staff members against using students to fill in.

- Anyone can volunteer to cover the needed hours.

- Volunteers will consider their own deadlines and critical obligations.

- Volunteers will check with their supervisor and keep their home unit informed of their volunteer location and schedule.

- No unit will be left without coverage.

\section{Conclusion}

Cross-training does not solve all problems. When being short-staffed is a chronic condition, moving individuals from unit to unit and task to task will only keep the fires under control. Site visits and cross-training make clear both the complexities of all library work and the difficulty of mastering more than basic skills in brief taining sessions. Nevertheless, crosstraining has been a well-received and successful program in SPCL. The benefits outlined at the beginning of this article have accrued to individuals and to the libraries. A cadre of trained staff members is available to step in and help when the need arises. Units are not reluctant to ask for help-they know people are prepared and interested. Knowledge gained working on other units enhances work in home units. The comination of site visits and crosstraining has strengthened a sense of community in a geographically dispersed and functionally separated organization. Cross-trained staff members are now an essential part of services and operations at SPCL. 


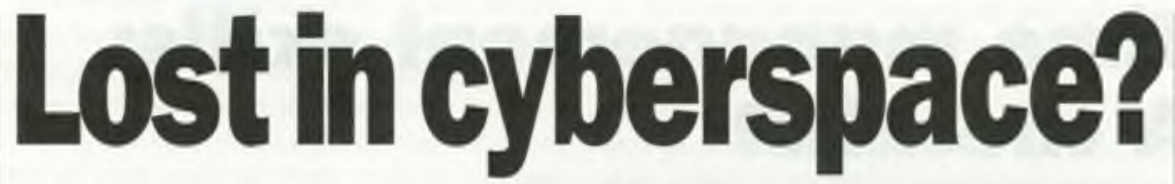

\section{Come to Engineering Information Village." We've mapped a way to save you time.}

It's Ei Village, a unique Internet community filled with cybertime-saving advantages for technical professionals and managers. Because information that can make a difference might reside anywhere. Quick-click connect to 12,000 WWW sites, prescreened for reliability and substantiveness, monitored, and described in Ei-authored annotations. There are Editor's Choices, current awareness services and an engineering peer community. There are special librarians, documents via e-mail and even an Ei Village Directory to help you quickly find technical news and other information. What's more, you'll get Engineering Management Journal, delivered electronically.

Within the Village Ei oflers friendly desktop access to over 150 databases, plus unlimited access to ILI StandardsWeb and Ei CompendexWeb. And there's more. But see for yourself:

\section{Try it free.}

To take up free Ei Village residency for one month, visit the Ei home page at URL http://www.ei.org. Or contact Engineering Information Inc. at 1 Castle Point Terrace Hoboken, NJ 07030 USA fax 201-216-8532, phone 800-221-1044 e-mail <ei®ei_orgs



\section{Engineering Information Inc. The data you need in the form you want}



